\title{
Impact of weight cycling on CTRP3 expression, adipose tissue inflammation and insulin sensitivity in $\mathrm{C57BL} / 6 \mathrm{~J}$ mice
}

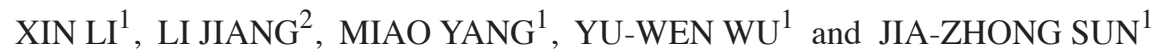 \\ Departments of ${ }^{1}$ Endocrinology and ${ }^{2}$ Internal Medicine, Zhongnan Hospital, \\ Wuhan University, Wuhan, Hubei 430071, P.R. China
}

Received June 29, 2017; Accepted May 11, 2018

DOI: $10.3892 /$ etm.2018.6399

\begin{abstract}
Impacts of weight cycling on C1q/tumor necrosis factor (TNF)-related protein-3 (CTRP3) expression, adipose tissue inflammation and insulin sensitivity in $\mathrm{C} 57 \mathrm{BL} / 6 \mathrm{~J}$ mice were evaluated in the current study. A total of 30 male $\mathrm{C} 57 \mathrm{Bl} / 6 \mathrm{~J}$ mice were divided randomly into three groups; normal control $(n=10)$, high-fat diet $(O B, n=10)$ and weight cycling (WC, $\mathrm{n}=10$ ), which were fed with high-fat diet in the first and last 8 weeks and regular chow in between. Systemic glucose metabolic status and insulin sensitivity were detected by intraperitoneal glucose tolerance test and hyperinsulinemic-euglycemic clamp, respectively. Blood levels of interleukin (IL)- 6 and TNF- $\alpha$ were determined using ELISA. Relative CTRP3, IL-6, TNF- $\alpha$ and glucose transporter (GLUT)4 mRNA expression in adipose tissue was detected using reverse transcription-quantitative polymerase chain reaction assays. Relative CTRP3, phosphatidylinositide 3-kinases (PI3K) and protein kinase B (PKB; Ser473) protein expression were detected by western blot analysis. Area under the curve of glucose and glucose infusion rate of the WC group were significantly increased compared with the OB group $(\mathrm{P}<0.01)$. CTRP3 mRNA and protein levels of the WC group were significantly decreased by 20.3 and $23.1 \%$, respectively, compared with the OB group $(\mathrm{P}<0.01)$. IL-6 and TNF- $\alpha$ protein plasma levels and gene expression in adipose tissue of the WC group were significantly increased compared with the OB group $(\mathrm{P}<0.01)$. Expression and phosphorylation of insulin signaling molecules PI3K and PKB (Ser473), respectively and GLUT4 gene expression in adipose tissue of the WC group were significantly decreased compared with the OB group $(\mathrm{P}<0.01)$. In conclusion, weight cycling impaired glucose metabolism and insulin sensitivity by decreasing CTRP3,
\end{abstract}

Correspondence to: Dr Xin Li, Department of Endocrinology, Zhongnan Hospital, Wuhan University, 169 Donghu Road, Wuhan, Hubei 430071, P.R. China

E-mail:wdy2003win@163.com

Key words: weight cycling, C1q/tumor necrosis factor-related protein-3, inflammation, insulin resistance, insulin signaling
PI3K, phosphorylated-PKB (Ser473) and GLUT4 expression, and increasing IL- 6 and TNF- $\alpha$ levels.

\section{Introduction}

Prevalence of overweight and obesity has rapidly increased in recent decades and is associated with increased risk of chronic diseases, including insulin resistance (IR), type 2 diabetes mellitus (T2DM) and cardiovascular disease (CAD) (1). The majority of metabolic consequences of obesity originate in dysfunction of adipose tissues (2). Losing weight is the most effective approach to counteract these negative consequences, through changes in lifestyle or surgery (3). Improved health or appearance encourages obese and non-obese individuals to lose weight through dietary changes or exercise (4). However, weight loss is rarely maintained (5). Repetitive loss and gain of body weight, which is defined as weight cycling, is very common (6). In developed countries $10-40 \%$ of the population are estimated to weight cycle (7). Impacts of weight cycling on the metabolism are controversial; studies indicate that weight cycling increases the risk of T2DM and CADs (8-10). Underlying mechanisms remain unknown.

Obesity is considered a low-grade chronic inflammatory disease (11). Increased proinflammatory cytokines are expressed in hypertrophied adipocytes and adipose tissue-resident immune cells (12). Metabolic inflammation is considered to be a pivotal factor in the pathogenesis of IR and T2DM, and white adipose tissue is the main source of systemic low-grade inflammation (13). It is well-known that the primary function of adipose tissue is to store excess nutrients, including triglycerides (TGs) and release free fatty acids (FFAs) during fasting (14). To date, $>50$ adipokines have been reported (15). Adipokines exert their biological roles through autocrine, paracrine or systemic mechanism, modulating physiological processes of metabolism and immunity (16). C1q/tumor necrosis factor (TNF)-related protein-3 (CTRP3) is a novel adipokine expressed in subcutaneous and visceral adipose tissue (17). CTRP3 has been reported to have multiple effects, including lowering glucose levels, inhibiting glyconeogenesis in the liver (18), increasing angiogenesis (19) and anti-inflammation (20). Expression is upregulated by insulin and downregulated by chronic lipopolysaccharide exposure (21). Impacts of weight cycling on adipokine expression, including leptin, adiponectin and resistin, have been 
reported (22). Associations with CTRP3 expression, which may affect metabolic consequences of weight cycling by modulating inflammation and insulin signaling transduction, have yet to be evaluated.

In the present study, C57BL/6J mice were cycled between high-fat diet and standard chow to determine if weight cycling alters CTRP3 expression, inflammation and insulin sensitivity compared with a normal control (NC) group that gained weight in the absence of weight cycling.

\section{Materials and methods}

Animals and diets. A total of 30 8-week-old healthy male C57Bl/6J mice (body weight, 20.0 $\pm 1.0 \mathrm{~g}$ ) were housed under 12-h light/dark cycles with regulated temperature $\left(18-25^{\circ} \mathrm{C}\right)$ and humidity (55-65\%). Mice were purchased from the Beijing Vital River Laboratory Animal Technology Co., Ltd. (Beijing, China). All mice received ad libitum access to food and water, and were fed with regular chow for 2 weeks to adapt to the environment. Contents of the regular chow were $21 \%$ protein, $55 \%$ carbohydrate and $6 \%$ fat, with a total energy of $15.36 \mathrm{~kJ} / \mathrm{g}$. Following the initial 2 weeks, mice were divided randomly into the NC group $(n=10)$, fed with regular chow throughout the study ( 24 weeks); the obesity group (OB; $n=10)$, fed with high-fat diet which consisted of regular feedstuff, lard, sucrose, milk powder and fresh egg, with a final composition of $16 \%$ protein, $38 \%$ carbohydrate and $46 \%$ fat and a total energy of $20.54 \mathrm{~kJ} / \mathrm{g}$ throughout the study (24 weeks) (23); and the weight cycling group (WC, $n=10)$ with a diet-switch protocol (24), where mice were fed with the high-fat diet in the first and last 8 weeks and regular chow for the remainder of the study. All experimental procedures were approved by the Institutional Animal Care and Use Committee of the Center for Animal Experiments, Wuhan University (Wuhan, China).

Body mass, food intake and feed efficiency. Mice had free access to food and water. Body mass (BM) was determined weekly throughout the study. Mice were provided with fresh chow every morning; chow remaining from the previous day was discarded after the mass was recorded. Differences between food supplied and remaining were considered as food intake (FI). Feed efficiency (FE) was calculated as ratio between $\mathrm{BM}$ gain $(\mathrm{g})$ and food consumed $(\mathrm{kJ})$ per animal over the course of the study (every 8 weeks), and is presented as a percentage (24).

Intraperitoneal glucose tolerance tests. After 24 weeks, baseline blood glucose of mice was measured from blood of the tail vein followed by $8 \mathrm{~h}$ fasting. An intraperitoneal injection of $10 \%$ glucose solution at $0.01 \mathrm{ml} / \mathrm{g}$ body weight was administered to the mice. Time points of blood glucose measurements were $0,30,60,120$ and $180 \mathrm{~min}$ following injection. Levels of glucose were detected using a Glucose assay kit (cat. no. F006; Nanjing Jiancheng Bioengineering Institute, Nanjing, China) according to the manufacturer's protocol. The trapezoidal method was used to calculate the area under the curve of glucose (AUCG) (23).

Hyperinsulinemic-euglycemic clamp. At week 24, mice were anesthetized with pentobarbitone $(50 \mathrm{mg} / \mathrm{kg})$ via intraperitoneal injection following overnight fasting. Both sides of femoral veins were exposed and catheters for glucose and insulin infusions were inserted. A further catheter was inserted into the femoral artery for blood sampling. After the surgery was performed, mice were placed quietly without any further operation for $30 \mathrm{~min}$ to eliminate any possible stress. Then the hyperinsulinemic-euglycemic clamping test was performed, which lasted $120 \mathrm{~min}$. The insulin infusion rate was $1.67 \mathrm{mU} / \mathrm{kg} / \mathrm{min}$ and the arterial blood glucose level was clamped at the basal fasting concentration by supplying glucose at variable rates. Under hyperinsulinemic conditions, the steady glucose infusion rate (GIR) required to maintain euglycemia is a standard measure of systemic insulin sensitivity (25).

Blood measurements. Total cholesterol (TC), FFAs and TGs were detected using a total cholesterol assay kit, a nonesterified free fatty acid assay kit and a triglyceride assay kit all obtained from Nanjing Jiancheng Bioengineering Institute (cat. nos. F002-2, A042-2 and F001, respectively). Interleukin (IL)-6 (cat. no. ab100713) and TNF- $\alpha$ (cat. no. ab1793) were assessed using commercially available ELISA kits obtained from Abcam, (Cambridge, UK) according to the manufacturer's protocol. The concentrations of TNF- $\alpha$ and IL-6 in each sample were determined by interpolation from the standard curve. The intra-essay precision and inter-assay precision were $<6$ and $<10 \%$, respectively.

Adipose tissue histology. At week 24, all animals were euthanized by $\mathrm{CO}_{2}$ inhalation. A comprehensive assessment of death was made through observation of signs of breath, heartbeat and nerve reflex. One side of the epididymal fat was extracted from sacrificed mice. Tissue was weighed, divided into four equal pieces and fixed overnight at $4^{\circ} \mathrm{C}$ by immersion in phosphate-buffered $4 \%$ paraformaldehyde. Samples were dehydrated and embedded in paraffin. Embedded tissue was cut into 5 - $\mu \mathrm{m}$-thick sections for hematoxylin and eosin staining. Sections were routinely de-waxed with xylene for $30 \mathrm{~min}$, followed by gradient ethanol dehydration with 100, 95, 85 and $70 \%$ ethanol for $2 \mathrm{~min}$. The tissue sections were then immersed in hematoxylin at room temperature for $15 \mathrm{~min}$, in $1 \%$ hydrochloric alcohol for 6-8 sec and in saturated lithium carbonate solution for $1 \mathrm{~min}$. Then, the tissue sections were immersed in eosin staining solution for $4 \mathrm{~min}$ (26). Six light microscopic images (magnification, $x 400$ ) per mouse and 5 mice per group were selected at random for the quantitative analysis with Image $\mathrm{J}$ (version 1.52a; National Institutes of Health, Bethesda, MD, USA) and the average adipocyte volume $\left(\mu \mathrm{m}^{2}\right)$ was extrapolated (27).

Reverse transcription-quantitative polymerase chain reaction $(R T-q P C R)$. Fresh epididymal adipose tissue was homogenized with RLT lysis buffer (Rneasy Mini kit; Qiagen, Inc., Valencia, CA, USA) followed by chloroform delipidation steps. Total RNA was extracted from the aqueous phase using a silicon spin column. cDNA was reverse-transcribed with SuperScript III (Invitrogen; Thermo Fisher Scientific, Inc., Waltham, MA, USA) using $1 \mu \mathrm{g}$ total RNA, according to the manufacturer's instructions. PCR primers (Shanghai Saibaisheng Gene Technology Co. Ltd., Shanghai, China) used 
in the present study were as follows: CTRP3, forward 5'-GCC CCCGTATCAGGTGTGTATTT-3' and reverse 5'-TGAAGA CTGTGTTGCCGTTGTGC-3'; IL-6, forward 5'-AGTTGC CTTCTTGGGACTGA-3' and reverse 5'-CAGAATTGCCAT TGCACAAC-3'; TNF- $\alpha$, forwards 5'-ACGGCATGGATC TCAAAGAC-3' and reverse 5'-CGGCAGAGACCACCTTGA ACT-3'; glucose transporter (GLUT)4, forward 5'-CCCCGC TGGAATGAGGTTTTTGAGGTGAT-3' and reverse 5'-CAG ACAGGGGCCGAAGATTGGGAGACAGT- 3 '; and $\beta$-actin, forward 5'-ACACCCGCCACCAGTTCGC-3' and reverse 5'-TCTCCCCCTCATCACCCACAT-3'. $\beta$-actin mRNA was quantified as internal control. Analysis was performed using the $2^{-\Delta \Delta \mathrm{Cq}}$ method (28). Cycle conditions were $95^{\circ} \mathrm{C}$ for $2 \mathrm{~min}$ followed by 40 cycles at $95^{\circ} \mathrm{C}$ for $15 \mathrm{sec}$ and $65^{\circ} \mathrm{C}$ for $34 \mathrm{sec}$.

Western blot analysis. Proteins of epididymal adipose tissue homogenates were prepared by adding $30 \mu \mathrm{l} / \mathrm{ml}$ protease inhibitors (Roche Applied Science, Penzberg, Germany) and $10 \mu \mathrm{l} / \mathrm{ml}$ phosphatase inhibitors (Sigma-Aldrich; Merck KGaA, Darmstadt, Germany) in tissue extraction reagent I (cat. no. FNN0071; Thermo Fisher Scientific, Inc.). The protein concentration was determined using a BCA protein assay kit (Pierce; Thermo Fisher Scientific, Inc.). Samples were heated to $100^{\circ} \mathrm{C}$ for $5 \mathrm{~min}$ in SDS buffer (cat. no. orb154330; Biorbyt Ltd., Cambridge, UK) and equal volumes of protein extracts $(25 \mu \mathrm{g})$ were separated on 12\% SDS-PAGE gels and transferred to polyvinylidene fluoride membranes. Membranes were blocked with 5\% skimmed milk in Tris-buffered saline containing $0.1 \%$ Tween-20 (TBS-T) for $1 \mathrm{~h}$ at $20^{\circ} \mathrm{C}$, followed by incubation overnight at $4^{\circ} \mathrm{C}$ with the following affinity-purified goat polyclonal primary antibodies obtained from Abcam: CTRP3 (cat. no. ab135301; 1:1,000), phosphatidylinositide 3-kinases (PI3K; cat. no. ab86714; 1:1,000), phosphorylated protein kinase B (p-PKB)-Ser473 (cat. no. ab18206; 1:1,000), PKB (cat. no. ab8805; 1:1,000) and $\beta$-actin: (cat. no. ab8226; 1:1,000). Horseradish peroxidase-conjugated goat anti-rabbit immunoglobulin G (1:5,000; cat. no. CL7802AP; Cedarlane Laboratories, Burlington, Canada) conjugated to horseradish peroxidase was incubated with membranes for $1 \mathrm{~h}$ at room temperature. Following five washes with TBS-T, membranes were processed for autoradiography by enhanced chemiluminescence (Pierce; Thermo Fisher Scientific, Inc.). Densitometric analysis was performed using ImageQuant (version LAS-4000; GE Healthcare Life Sciences, Little Chalfont, UK). Experiments were performed in triplicates.

Statistical analysis. Data are presented as mean \pm standard error and were evaluated statistically by one-way analysis of variance (ANOVA) with SPSS (19.0; IBM Corp., Armonk, NY, USA). Comparisons among three groups were performed by one-way ANOVA followed by Bonferroni's post-hoc tests. $\mathrm{P}<0.05$ was considered to indicate a statistically significant difference.

\section{Results}

Changes in BM during the experiment. Changes in $\mathrm{BM}$ of mice throughout the experiment are presented in Fig. 1. At the beginning of the study, no significant differences in BM among the groups were observed. During the first 8 weeks, the BM of

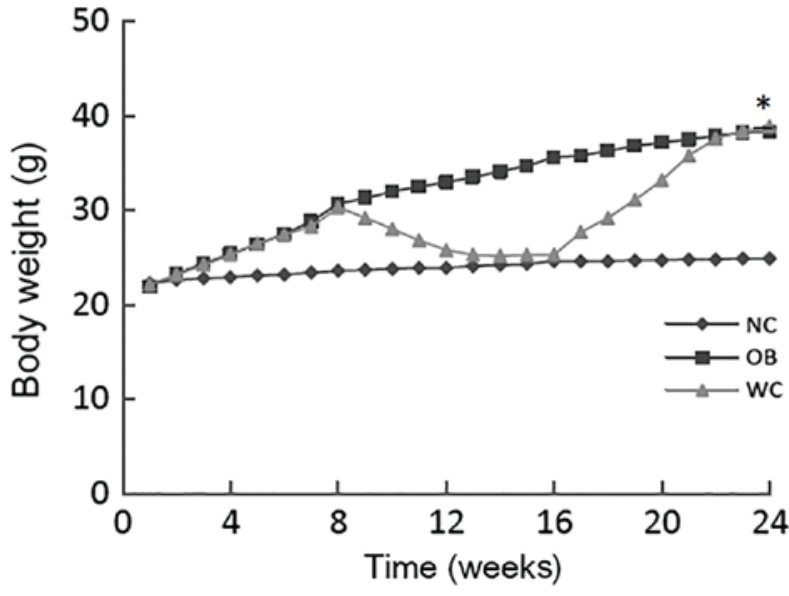

Figure 1. Changes in body weight of the mice. Mean body weight of mice following varying dieting regimes for 24 weeks was determined weekly. ${ }^{*} \mathrm{P}<0.01$ vs. NC group. NC, normal control; OB, obesity; WC, weight cycling.

mice in OB and WC groups, who were provided with high-fat diet, increased faster compared with the $\mathrm{NC}$ group, which was fed regular chow. Following the switch to regular chow in the WC group, BM decreased over the course of 4 weeks to match that of the $\mathrm{NC}$ group. Following the reintroduction of a high-fat diet at week 16, mice of the WC group regained weight and matched with the OB group in the final 3 weeks of the study. At the end of the study, BM of the OB and WC groups were significantly increased compared with the $\mathrm{NC}$ group $(\mathrm{P}<0.01)$. No significant difference in BM between OB and WC group was observed.

Weight cycling increases feed efficiency. Mice fed regular chow and high-fat diet had a similar FI (g/animal/day) throughout the study. The FE in the WC and OB groups was higher compared with the NC group $(\mathrm{P}<0.01)$. In the first 8 weeks, there were no significant differences in FE between the OB and WC group $(1.01 \pm 0.04 \mathrm{~g} / \mathrm{kJ}$ vs. $0.99 \pm 0.04 \mathrm{~g} / \mathrm{kJ})$; however, both were significantly higher than the NC group $(0.55 \pm 0.03 \mathrm{~g} / \mathrm{kJ}, \mathrm{P}<0.01)$. In the second phase of the study, the FE of the WC group was significantly lower than the OB group $(0.84 \pm 0.03 \mathrm{~g} / \mathrm{kJ}$ vs. $0.93 \pm 0.03 \mathrm{~g} / \mathrm{kJ} ; \mathrm{P}<0.05)$, but all remained significantly higher than the NC group $(0.49 \pm 0.03 \mathrm{~g} / \mathrm{kJ}$; $\mathrm{P}<0.01)$. In the last 8 weeks, $\mathrm{FE}$ in the WC group was significantly increased compared with the OB group $(1.05 \pm 0.05 \mathrm{~g} / \mathrm{kJ}$ vs. $0.87 \pm 0.03 \mathrm{~g} / \mathrm{kJ} ; \mathrm{P}<0.01$ ), indicating that the FE of WC mice was increased in the phase of body weight regaining (Table I).

Weight cycling impairs systemic glucose metabolism. At the end of the experiment, intraperitoneal glucose tolerance tests were performed to indicate levels of systemic glucose metabolism. High-fat dieting in the $\mathrm{OB}$ and WC group significantly increased blood glucose concentrations compared with regular chow in the NC group $(\mathrm{P}<0.01)$. Weight cycling resulted in an additional significant increase in blood glucose levels compared with the OB group $(\mathrm{P}<0.01$; Fig. 2). The AUCG from $0-180 \mathrm{~min}\left(\mathrm{AUCG}_{0-180}\right)$ determined for the $\mathrm{OB}$ and $\mathrm{WC}$ groups were significantly increased compared with the $\mathrm{NC}$ group $(\mathrm{P}<0.01)$. $\mathrm{AUCG}_{0-180}$ of the $\mathrm{WC}$ group was significantly increased compared with the OB group $(\mathrm{P}<0.01$; Table I), 
Table I. Food intake, feed efficiency, glucose tolerance, insulin sensitivity, blood fat and inflammation factors in serum of mice under varying dieting regimes $(n=10)$.

\begin{tabular}{|c|c|c|c|c|c|c|c|c|c|}
\hline Group & $\mathrm{FI}^{\mathrm{d}}(\mathrm{g} / \mathrm{animal} / \mathrm{d})$ & $\mathrm{FE}^{\mathrm{d}}(\mathrm{g} / \mathrm{kJ})$ & AUCG & $\begin{array}{c}\text { GIR } \\
(\mathrm{mg} / \mathrm{kg} / \mathrm{min})\end{array}$ & $\begin{array}{c}\text { FFA } \\
(\mathrm{mmol} / \mathrm{l})\end{array}$ & $\begin{array}{c}\mathrm{TG} \\
(\mathrm{mmol} / \mathrm{l})\end{array}$ & $\begin{array}{c}\mathrm{TC} \\
(\mathrm{mmol} / \mathrm{l})\end{array}$ & $\begin{array}{c}\text { IL-6 } \\
(\mathrm{pg} / \mathrm{ml})\end{array}$ & $\begin{array}{l}\text { TNF- } \alpha \\
(\mathrm{pg} / \mathrm{ml})\end{array}$ \\
\hline $\mathrm{NC}$ & $3.30 \pm 0.06$ & $0.37 \pm 0.02$ & $1,005 \pm 25$ & $10.30 \pm 0.98$ & $0.23 \pm 0.03$ & $0.65 \pm 0.06$ & $2.45 \pm 0.12$ & $25.4 \pm 2.4$ & $3.2 \pm 0.3$ \\
\hline OB & $3.29 \pm 0.05$ & $0.87 \pm 0.03^{\mathrm{a}}$ & $1,325 \pm 28^{\mathrm{a}}$ & $6.72 \pm 0.83^{\mathrm{a}}$ & $0.38 \pm 0.03^{\mathrm{a}}$ & $0.89 \pm 0.09^{\mathrm{a}}$ & $3.87 \pm 0.21^{\mathrm{a}}$ & $98.7 \pm 5.3^{\mathrm{a}}$ & $6.7 \pm 0.4^{\mathrm{a}}$ \\
\hline WC & $3.35 \pm 0.08$ & $1.05 \pm 0.05^{\mathrm{a}, \mathrm{b}}$ & $1,455 \pm 32^{\mathrm{a}, \mathrm{b}}$ & $5.30 \pm 0.72^{\mathrm{a}, \mathrm{b}}$ & $0.41 \pm 0.04^{\mathrm{a}}$ & $0.83 \pm 0.08^{a}$ & $4.12 \pm 0.29^{\mathrm{a}, \mathrm{c}}$ & $118.3 \pm 8.1^{\mathrm{a}, \mathrm{b}}$ & $8.1 \pm 0.6^{\mathrm{a}, \mathrm{b}}$ \\
\hline
\end{tabular}

${ }^{\mathrm{a}} \mathrm{P}<0.01$ vs. NC group; ${ }^{\mathrm{b}} \mathrm{P}<0.01$ vs. OB group; ${ }^{\mathrm{c}} \mathrm{P}<0.05$ vs. OB group. $\mathrm{NC}$, normal control; OB, obesity; WC, weight cycling; FI, food intake; FE, feed efficiency; AUCG, area under the curve of glucose; GIR, glucose infusion rate; FFA, free fatty acid; TG, triglyceride; TC, total cholesterol; IL-6, interleukin-6; TNF- $\alpha$, tumor necrosis factor- $\alpha .{ }^{\mathrm{d}}$ Week 17-24.

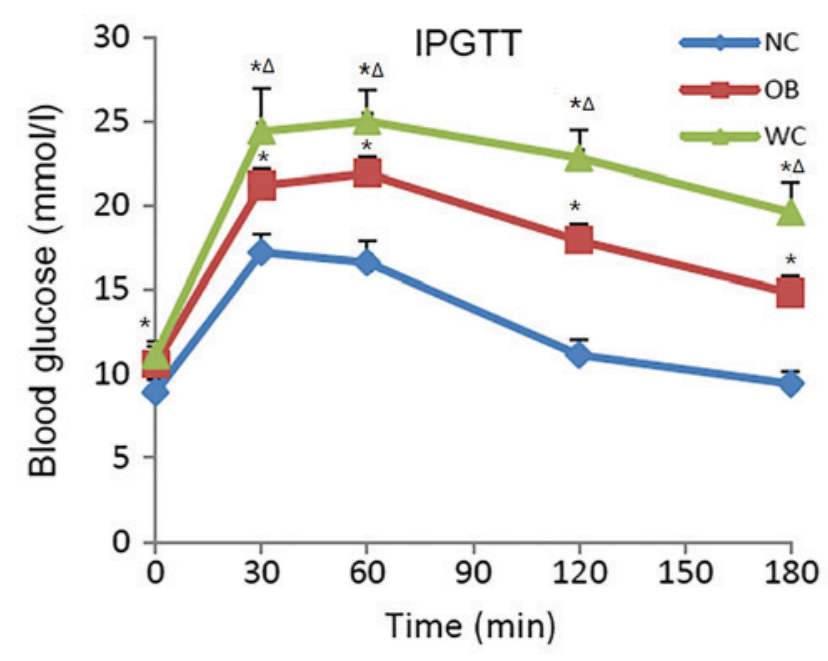

Figure 2. Weight cycling induces systemic glucose metabolic dysfunction. Blood glucose levels were determined over $180 \mathrm{~min}$ using IPGTT in mice following varying dieting regimes for 24 weeks. IPGTT, intraperitoneal glucose tolerance test; $\mathrm{NC}$, normal control; $\mathrm{OB}$, obesity; WC, weight cycling. ${ }^{*} \mathrm{P}<0.01$ vs. $\mathrm{NC}$ group, ${ }^{\Delta} \mathrm{P}<0.01$ vs. $\mathrm{OB}$ group.

indicating that weight cycling deteriorated metabolic dysfunction compared with continuous high-fat dieting.

Weight cycling impairs systemic insulin sensitivity. GIRs were used to evaluate insulin sensitivity. The GIR in the OB group was $6.72 \pm 0.83 \mathrm{mg} / \mathrm{kg} / \mathrm{min}$, which was significantly lower compared with the $\mathrm{NC}$ group at $10.3 \pm 0.98 \mathrm{mg} / \mathrm{kg} / \mathrm{min}(\mathrm{P}<0.01)$. These results indicated that a high-fat diet may induce systemic IR. Weight cycling resulted in an additional significant decrease in GIR compared with the OB group $(5.30 \pm 0.72 \mathrm{mg} / \mathrm{kg} / \mathrm{min}$ vs. $6.72 \pm 0.83 \mathrm{mg} / \mathrm{kg} / \mathrm{min}$; P<0.01; Table I).

Weight cycling increases serum lipid levels and inflammation factors. Levels of TG, FFA and TC in the OB and WC groups were significantly increased compared with the NC group $(\mathrm{P}<0.01)$. No significant differences in $\mathrm{TG}$ and FFA were observed between the OB and WC groups, whereas TC levels in the WC group were significantly increased compared with the OB group $(\mathrm{P}<0.05)$. Compared with the NC group, IL-6 and TNF- $\alpha$ blood levels in the OB and WC group were significantly increased $(\mathrm{P}<0.01)$. IL-6 and TNF- $\alpha$ in blood levels in

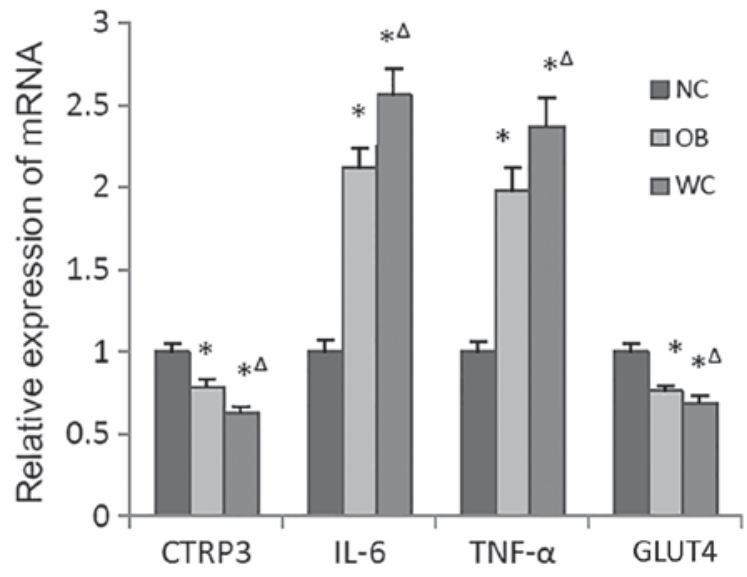

Figure 3. Effects of dieting on CTRP3, IL-6, TNF- $\alpha$ and GLUT4 mRNA expression. Relative CTRP3, IL-6, TNF- $\alpha$ and GLUT4 mRNA levels were determined in mice following varying dieting regimes for 24 weeks using reverse transcription-quantitative polymerase chain reaction assays. ${ }^{*} \mathrm{P}<0.01$ vs. NC group; ${ }^{\wedge} \mathrm{P}<0.01$ vs. OB group. TNF, tumor necrosis factor; CTRP3, C1q/TNF-related protein-3; IL-6, interleukin-6; GLUT4, glucose transporter 4; $\mathrm{NC}$, normal control; OB, obesity; WC, weight cycling.

the WC group were significantly increased compared with the OB group $(\mathrm{P}<0.01$; Table $\mathrm{I})$.

Weight cycling decreases CTRP3 expression in adipose tissue. Relative CTRP3 mRNA expression in adipose tissue of the OB and WC groups was significantly decreased compared with the NC group $(\mathrm{P}<0.01)$. CTRP3 mRNA expression in the WC group was significantly decreased by $20.3 \%$ compared with the OB group $(\mathrm{P}<0.01$; Fig. 3$)$. Compared with the NC group, relative CTRP3 protein expression in adipose tissue of the $\mathrm{OB}$ and WC groups was significantly decreased by 31.0 and $47.0 \%$, respectively ( $\mathrm{P}<0.01$; Fig. 4). Significant differences in CTRP3 protein expression in adipose tissue were further observed between the $\mathrm{OB}$ and the WC group $(\mathrm{P}<0.01)$.

Weight cycling increases adipocyte size and expression of inflammatory factors in adipose tissue. Adipocyte sizes in the $\mathrm{OB}$ and WC groups were significantly increased compared with the NC group $(\mathrm{P}<0.01)$. Compared with the OB group, the adipocyte size of the WC group was significantly increased by $48.42 \%(\mathrm{P}<0.01$; Fig. 5). Relative IL-6 and TNF- $\alpha$ mRNA 


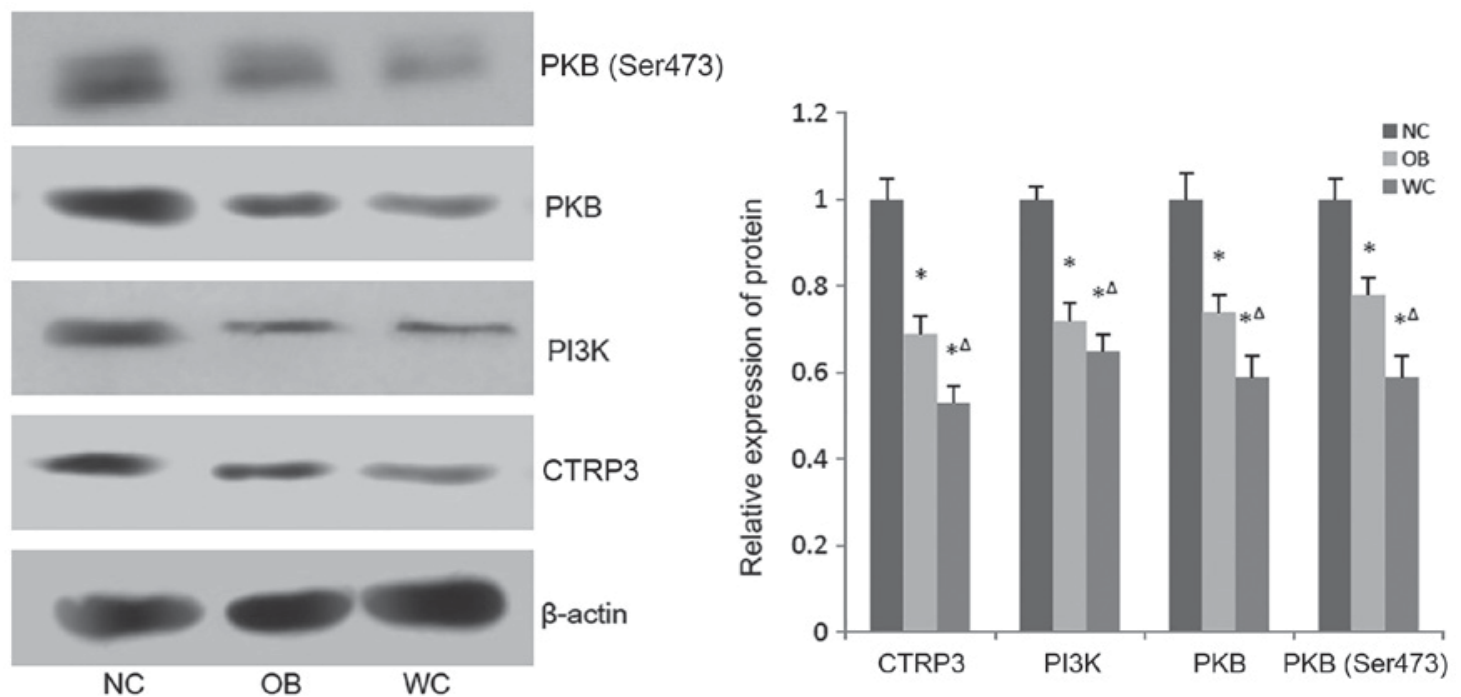

Figure 4. Effects of dieting on CTRP3, PI3K, PKB and PKB (Ser473) protein expression. Relative CTRP3, PI3K, PKB and PKB (Ser473) protein expression was determined in mice following varying dieting regimes for 24 weeks. ${ }^{*} \mathrm{P}<0.01$ vs. $\mathrm{NC}$ group; ${ }^{\wedge} \mathrm{P}<0.01$ vs. OB group. CTRP3, C1q/tumor necrosis factor-related protein-3; PI3K, phosphatidylinositol 3-kinase; PKB, protein kinase B; NC, normal control; OB, obesity; WC, weight cycling.
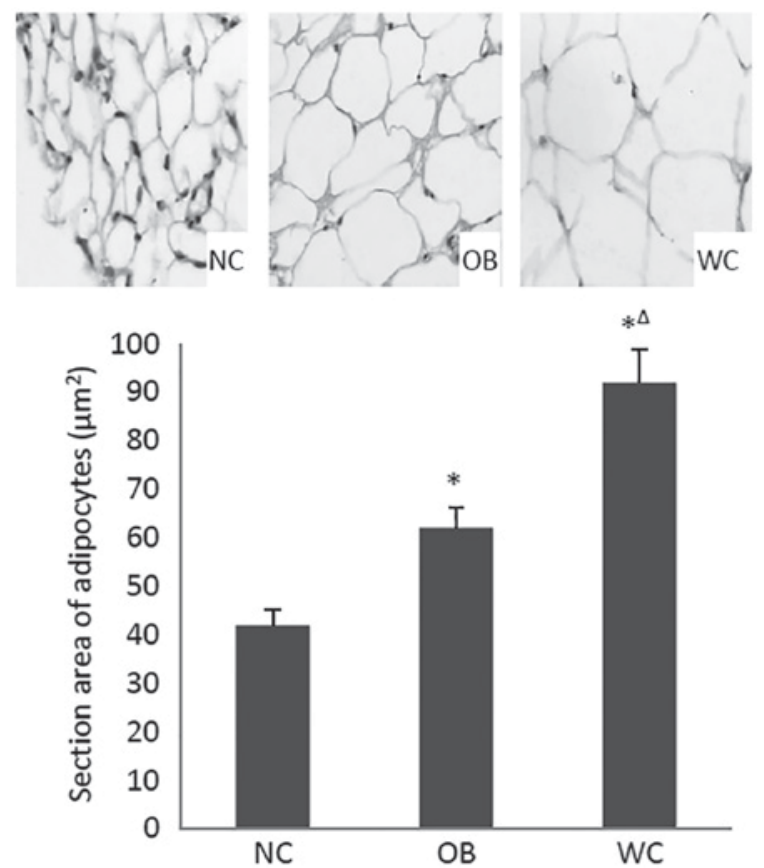

Figure 5. Effects of dieting on area of adipocytes. Section areas of adipocytes of mice following varying dieting regimes for 24 weeks were determined using hematoxylin and eosin staining (magnification, $\mathrm{x} 400$ ). ${ }^{*} \mathrm{P}<0.01$ vs. $\mathrm{NC}$ group; ${ }^{4} \mathrm{P}<0.01$ vs. OB group. NC, normal control; OB, obesity; WC, weight cycling.

expression in the $\mathrm{OB}$ and $\mathrm{WC}$ groups were significantly elevated compared with the $\mathrm{NC}$ group $(\mathrm{P}<0.01)$. Compared with the OB group, IL- 6 and TNF- $\alpha$ mRNA expression in the WC group was significantly increased by 20.8 and $19.7 \%$, respectively $(\mathrm{P}<0.01$; Fig. 3$)$.

Weight cycling decreases expression of insulin signaling molecules in adipose tissue. Compared with the NC group, relative PI3K expression and PKB (Ser473) phosphorylation in adipose tissue of the $\mathrm{OB}$ and WC groups were significantly decreased (P<0.01; Fig. 5). PI3K expression and PKB (Ser473) phosphorylation in adipose tissue of the WC group were significantly decreased by 9.7 and $24.4 \%$, respectively, compared with the OB group $(\mathrm{P}<0.01)$. Relative GLUT4 mRNA expression in the OB and WC group was decreased by 24.0 and $31.0 \%$, respectively, compared with the $\mathrm{NC}$ group $(\mathrm{P}<0.01$; Fig. 3$)$. Differences in relative GLUT4 mRNA expression between the WC and $\mathrm{OB}$ groups were significant $(\mathrm{P}<0.01)$.

\section{Discussion}

One of the features of obesity is low-grade inflammation, which attributes to dysregulated production and release of cytokines and adipokines, including IL- 6 , TNF- $\alpha$, monocyte chemoattractant protein 1, leptin, resistin and adiponectin (29). Controlling of body weight has an important effect on T2DM, CAD and other obesity-associated diseases (30). However, weight loss interventions are often accompanied by repeated weight loss and recovery cycles, a phenomenon known as weight cycling (31). A study has demonstrated that weight cycling is associated with deterioration of metabolism and CADs (32). However, the mechanism by which weight cycling promotes metabolic dysfunction remains unclear. The current study revealed that weight cycling worsened obesity-associated systemic glucose intolerance and IR in C57Bl/6J mice. In addition to worsened metabolic disorders, it was observed that weight cycling increased TNF- $\alpha$ and IL-6 mRNA expression in adipose tissue and decreased expression of insulin signaling molecules and CTRP3, a novel adipokine, which has been reported to have anti-inflammation and insulin sensitization effects (33). These findings indicated that dysregulated CTRP3 expression and associated aggravated inflammation in adipose tissue may describe possible mechanisms through which weight cycling induces metabolic dysfunction.

The current study demonstrated that body weight of the WC group increased to the level of the OB group at the end of the study. Mice experienced three cycles of diet. In the second cycle, regular chow followed a high-fat diet allowing the mice to recuperate their body weight. It has been demonstrated 
that caloric restriction of humans and rodents reduces energy consumption and makes it difficult to maintain weight loss (34). A reduction in energy expenditure may persist during weight loss, suggesting that a reduction in energy expenditure may be a metabolic defense for weight loss (35). This may explain large fluctuations in body weight observed in obese patients. In the current study, it was revealed that the FE in the last eight weeks in the WC group was significantly higher compared with the $\mathrm{OB}$ group, which was also fed with high-fat diet. This indicated that the FE of WC mice was increased in the phase of regaining body weight. Weight cycling may induce adverse metabolic outcomes through regaining body weight with increased FE.

A clinical study demonstrated that weight cycling increases the risk for development of T2DM and CAD (36). Another study reported that there was a $10 \%$ increase in 25 -year risk of coronary death in males with cycled weight compared with those with stable gained weight (37). A previous study demonstrated that weight cycling was associated with increased incidence of T2DM in participants of the Framingham Heart Study (38). However, other studies reported no adverse effects of weight cycling $(6,39,40)$. A study focused on the association between weight cycling and mortality and revealed that weight cycling, independent of body mass index and weight gain, did not increase the overall risk of mortality (41). The controversy of the impacts of weight cycling in humans may be due to varying study designs. In an animal study, it was reported that weight cycling resulted in an additional increase in fasting blood glucose levels and decrease in glucose tolerance compared with a weight gain group (42). In agreement with previous studies, the current study demonstrated that fasting blood glucose levels and $\mathrm{AUCG}_{0-180}$ of the weight cycling group were increased compared with the obesity group, indicating that weight cycling increases the overall metabolic disorder, even when compared with a high fat diet.

A previous study has revealed that weight cycling increases systemic IR in rats, through increased fasting insulin levels (43). To the best of our knowledge, the current study detected for the first time the system insulin sensitivity through hyperinsulinemic-euglycemic clamp. It revealed that high-fat dieting induced IR compared with regular chow, whereas weight cycling resulted in an additional increase in IR compared with the OB group. It was further reported that relative PI3K expression, PKB (Ser473) phosphorylation and GLUT4 gene expression in adipose tissue of the WC group were significantly decreased compared with the OB group. A previous study demonstrated that a complete loss of insulin stimulated AKT/PKB phosphorylation at Ser473 in adipose tissue of weight cycling mice following insulin injection, indicating that weight cycling further impaired adipose tissue insulin sensitivity compared with continuous obesity (42).

Macrophages are usually present in adipose tissue following the breakdown of adipocytes (44). A study reported that weight cycling induced a fluctuation of fat pads, potentially associated with immune cell infiltration and increased levels of proinflammatory cytokines and adipocyte IR (45). In accordance with previous studies, the current study demonstrated that weight cycling increased adipocyte size and relative IL-6 and TNF- $\alpha$ mRNA expression in adipose tissue. In addition to the activation of the innate immune system, another study reported that weight cycling increased CD4+ and CD8+ T cell counts, expression of type $1 \mathrm{~T}$ helper-associated cytokines and presence of CD8+ effector memory $\mathrm{T}$ cells in adipose tissue, suggesting an exaggerated adaptive immune response during weight cycling (42).

As the largest endocrine organ, adipose tissue secretes many bioactive molecules, including adipokines that circulate in blood (46). Adipokines serve important roles in energy homeostasis, obesity and diabetes (47). Adiponectin and resistin are currently discussed as key metabolic regulators in obesity, IR and T2DM (48). The concentration of circulating adiponectin, a potent anti-inflammatory effector, decreases as obesity progresses (49). Resistin is a unique signaling molecule that contributes to IR and is closely associated with inflammation markers (50). It has been reported that weight cycling decreased adiponectin expression and increased resistin expression, suggesting that weight cycling may induce metabolic disorders through dysregulation of adipokine expression (43). As a novel adipokine, CTRP3 has many effects, including lowering glucose levels, inhibiting glyconeogenesis in the liver (18), increasing angiogenesis (19) and anti-inflammation (51). A previous study revealed that CTRP3 improves insulin sensitivity of IR 3T3-L1 adipocytes by reducing inflammation and improving insulin signaling transduction (25). Effects of weight cycling on CTRP3 expression remain unknown. To the best of out knowledge, the current study, for the first time, reported that weight cycling decreased CTRP3 expression in adipose tissue.

There are potential limitations of the study. The frequency of weight cycling was limited to one cycle, obesity to weight loss to weight regain, biochemical parameters and the expression of inflammatory markers were only measured at the end of the study. Future studies may construct a model with increased weight cycling phases and investigate effects of weight cycling at various time points throughout the model.

In conclusion, the current study demonstrated that weight cycling impaired glucose tolerance and insulin sensitivity with decreased PKB (Ser473) phosphorylation, CTRP3 and PI3K protein and GLUT4 gene expression and increased IL-6 and TNF- $\alpha$ gene expression. Crosstalk between insulin and inflammation signaling is well-known; Jun N-terminal kinase-1 and inhibitor of $\kappa \mathrm{B}$ kinase are inflammatory signaling pathways that promote insulin resistance (52). Activation of these pathways will lead to serine phosphorylation of the insulin receptor substrate protein-1, resulting in diminished insulin effectiveness (53). Weight cycling may potentially aggravate glucose intolerance of obese mice through downregulation of anti-inflammation adipokine CTRP3 expression. Further studies are needed to determine signal transduction and molecular mechanisms supporting this hypothesis.

\section{Acknowledgements}

The authors would like to thank Ms Shuhan Li for her help with linguistic modifications to the manuscript.

\section{Funding}

The present study was supported by the Hubei Province Health and Family Planning Scientific Research Project (grant no. WJ2015Q018) and the Hubei Province Natural Science Foundation (grant no. 2016CFB662). 


\section{Availability of data and materials}

All data generated or analyzed during the present study are included in this published article.

\section{Authors' contributions}

XL designed and directed the research, and drafted the manuscript. XL, LJ and MY performed the experiments, and analyzed and interpreted data. YW and JS collected the experimental data. All authors read and approved the final for publication.

\section{Ethics approval and consent to participate}

All experimental procedures were approved by the Institutional Animal Care and Use Committee (IACUC) at the Center for Animal Experiments, Wuhan University (Wuhan, China).

\section{Patient consent for publication}

Not applicable.

\section{Competing interests}

The authors declare that they have no competing interests.

\section{References}

1. Nathan DM: Diabetes: Advances in diagnosis and treatment. JAMA 314: 1052-1062, 2015.

2. Stanford KI, Middelbeek RJ and Goodyear LJ: Exercise effects on white adipose tissue: Beiging and metabolic adaptations Diabetes 64: 2361-2368, 2015.

3. Chang YY and Chiou WB: Means yield to ends in weight loss: Focusing on 'how' vs 'why' aspects of losing weight can lead to poorer regulation of dietary practices. J Acad Nutr Diet 115: 1387-1391, 2015.

4. Bertz F, Brekke HK, Ellegård L, Rasmussen KM, Wennergren M and Winkvist A: Diet and exercise weight-loss trial in lactating overweight and obese women. Am J Clin Nutr 96: 698-705, 2012.

5. Melby CL, Paris HL, Foright RM and Peth J: Attenuating the biologic drive for weight regain following weight loss: Must what goes down always go back up? Nutrients 9pii: E468, 2017.

6. Bosy-Westphal A, Kahlhöfer J, Lagerpusch M, Skurk T and Müller MJ: Deep body composition phenotyping during weight cycling: Relevance to metabolic efficiency and metabolic risk. Obes Rev 1 (Suppl 16): S36-S44, 2015.

7. Delahanty LM, Pan Q, Jablonski KA, Aroda VR, Watson KE, Bray GA, Kahn SE, Florez JC, Perreault L, Franks PW and Diabetes Prevention Program Research Group: Effects of weight loss, weight cycling, and weight loss maintenance on diabetes incidence and change in cardiometabolic traits in the diabetes prevention program. Diabetes Care 37: 2738-2745, 2014.

8. Neamat-Allah J, Barrdahl M, Hüsing A, Katzke VA, Bachlechner U, Steffen A, Kaaks R, Schulze MB, Boeing H and Kühn T: Weight cycling and the risk of type 2 diabetes in the EPIC-Germany cohort. Diabetologia 58: 2718-2725, 2015.

9. Rhee EJ, Cho JH, Kwon H, Park SE, Park CY, Oh KW, Park SW and Lee WY: Increased risk of diabetes development in individuals with weight cycling over 4 years: The kangbuk samsung health study. Diabetes Res Clin Pract 139: 230-238, 2018.

10. Madigan CD, Pavey T, Daley AJ, Jolly K and Brown WJ: Is weight cycling associated with adverse health outcomes? A cohort study. Prev Med 108: 47-52, 2018.

11. Rogero MM and Calder PC: Obesity, inflammation, toll-like receptor 4 and fatty acids. Nutrients 10: pii: E432, 2018

12. Persson PB and Bondke Persson A: Metabolism, obesity and the metabolic syndrome. Acta Physiol (Oxf) 13: e13096, 2018.
13. Tarantino G: Gut microbiome, obesity-related comorbidities, and low-grade chronic inflammation. J Clin Endocrinol Metab 99: 2343-2346, 2014.

14. Ryan DH and Jensen MD: What the new obesity guidelines will tell us. Curr Opin Endocrinol Diabetes Obes 20: 429-433, 2013.

15. Boutari C, Perakakis N and Mantzoros CS: Association of adipokines with development and progression of nonalcoholic fatty liver disease. Endocrinol Metab (Seoul) 33: 33-43, 2018.

16. Andrade-Oliveira V, Câmara NO and Moraes-Vieira PM: Adipokines as drug targets in diabetes and underlying disturbances. J Diabetes Res 2015: 681612, 2015.

17. Li Y, Wright GL and Peterson JM: Clq/TNF-related protein 3 (CTRP3) function and regulation. Compr Physiol 7: 863-878, 2017.

18. Peterson JM, Wei Z and Wong GW: C1q/TNF-related protein-3 (CTRP3), a novel adipokine that regulates hepatic glucose output. J Biol Chem 285: 39691-39701, 2010.

19. Yi W, Sun Y, Yuan Y, Lau WB, Zheng Q, Wang X, Wang Y, Shang X, Gao E, Koch WJ and Ma XL: C1q/tumor necrosis factor-related protein-3, a newly identified adipokine, is a novel antiapoptotic, proangiogenic, and cardioprotective molecule in the ischemic mouse heart. Circulation 125: 3159-3169, 2012.

20. Petersen PS, Wolf RM, Lei X, Peterson JM and Wong GW: Immunomodulatory roles of CTRP3 in endotoxemia and metabolic stress. Physiol Rep 4: e12735, 2016.

21. Li X, Jiang L, Yang M, Wu YW, Sun JZ and Sun SX: CTRP3 improves the insulin sensitivityof 3T3-L1 adipocytes by inhibiting inflammation and ameliorating insulin signalling transduction. Endokrynol Pol 65: 252-258, 2014.

22. List EO, Berryman DE, Wright-Piekarski J, Jara A, Funk K and Kopchick JJ: The effects of weight cycling on lifespan in male C57BL/6J mice. Int J Obes (Lond) 37: 1088-1094, 2013.

23. Li X, Yuan L, Li J, Li H and Cheng S: Blockade of renin angiotensin system increased resistance to STZ-induced diabetes in rats with long-term high-fat diet. Exp Diabetes Res 2012: 618923, 2012.

24. Barbosa-da-Silva S, Fraulob-Aquino JC, Lopes JR, Mandarim-de-Lacerda CA and Aguila MB: Weight cycling enhances adipose tissue inflammatory responses in male mice. PLoS One 7: e39837, 2012.

25. Li X, Jiang L, Yang M, Wu YW, Sun SX and Sun JZ: Expression of CTRP3, a novel adipokine, in rats at different pathogenic stages of type 2 diabetes mellitus and the impacts of GLP-1 receptor agonist on it. J Diabetes Res 2014: 398518, 2014.

26. Zhou S, Wang G and Zhang W: Effect of TLR4/MyD88 signaling pathway on sepsis-associated acute respiratory distress syndrome in rats, via regulation of macrophage activation and inflammatory response. Exp Ther Med 15: 3376-3384, 2018.

27. Dankel SN, Degerud EM, Borkowski K, Fjære E, Midtbø LK, Haugen C, Solsvik MH, Lavigne AM, Liaset B, Sagen JV, et al: Weight cycling promotes fat gain and altered clock gene expression in adipose tissue in C57BL/6J mice. Am J Physiol Endocrinol Metab 306: E210-E224, 2014.

28. Livak KJ and Schmittgen TD: Analysis of relative gene expression data using real-time quantitative PCR and the 2(-Delta Delta C(T)) method. Methods 25: 402-408, 2001.

29. Tsai S, Clemente-Casares X, Revelo XS, Winer S and Winer DA: Are obesity-related insulin resistance and type 2 diabetes autoimmune diseases? Diabetes 64: 1886-1897, 2015.

30. Neeland IJ, Poirier P and Després JP: Cardiovascular and metabolic heterogeneity of obesity: Clinical challenges and implications for management. Circulation 137: 1391-1406, 2018.

31. Strohacker K and McFarlin BK: Influence of obesity, physical inactivity, and weight cycling on chronic inflammation. Front Biosci (Elite Ed) 2: 98-104, 2010.

32. Salinardi TC, Batra P, Roberts SB, Urban LE, Robinson LM, Pittas AG, Lichtenstein AH, Deckersbach T, Saltzman E and Das SK: Lifestyle intervention reduces body weight and improves cardiometabolic risk factors in worksites. Am J Clin Nutr 97: 667-676, 2013.

33. Wolf RM,Steele KE, Peterson LA, Magnuson TH, Schweitzer MA and Wong GW: Lower circulating C1q/TNF-related protein-3 (CTRP3) levels are associated with obesity: A cross-sectional study. PLoS One 10: e0133955, 2015.

34. Catenacci VA, Pan Z, Ostendorf D, Brannon S, Gozansky WS, Mattson MP, Martin B, MacLean PS, Melanson EL and Troy Donahoo W: A randomized pilot study comparing zero-calorie alternate-day fasting to daily caloric restriction in adults with obesity. Obesity (Silver Spring) 24: 1874-1883, 2016. 
35. Madero M, Arriaga JC, Jalal D, Rivard C, McFann K, Pérez-Méndez O, Vázquez A, Ruiz A, Lanaspa MA, Jimenez CR, et al: The effect of two energy-restricted diets, a low-fructose diet versus a moderate natural fructose diet, on weight loss and metabolic syndrome parameters: A randomized controlled trial. Metabolism 60: 1551-1559, 2011.

36. Kodama S, Horikawa C, Fujihara K, Yoshizawa S, Yachi Y, Tanaka S, Ohara N, Matsunaga S, Yamada T, Hanyu O and Sone H: Quantitative relationship between body weight gain in adulthood and incident type 2 diabetes: A meta-analysis. Obes Rev 15: 202-214, 2014.

37. Mehta T, Smith DL Jr, Muhammad J and Casazza K: Impact of weight cycling on risk of morbidity and mortality. Obes Rev 15: 870-881, 2014.

38. Abraham TM, Pencina KM, Pencina MJ and Fox CS: Trends in diabetes incidence: The framingham heart study. Diabetes Care 38: 482-487, 2015.

39. Mackie GM, Samocha-Bonet D and Tam CS: Does weight cycling promote obesity and metabolic risk factors? Obes Res Clin Pract 11: 131-139, 2017.

40. Zhang Y, Yatsuya H, Li Y, Chiang C, Hirakawa Y, Kawazoe N, Tamakoshi K, Toyoshima $\mathrm{H}$ and Aoyama A: Long-term weight-change slope, weight fluctuation and risk of type 2 diabetes mellitus in middle-aged Japanese men and women: Findings of aichi workers' cohort study. Nutr Diabetes 7: e252, 2017.

41. Stevens VL, Jacobs EJ, Sun J, Patel AV, McCullough ML, Teras LR and Gapstur SM: Weight cycling and mortality in a large prospective US study. Am J Epidemiol 175: 785-792, 2012.

42. Anderson EK, Gutierrez DA, Kennedy A and Hasty AH: Weight cycling increases T-cell accumulation in adipose tissue and impairs systemic glucose tolerance. Diabetes 62: 3180-3188, 2013.

43. Hoevenaars FP, Keijer J, Swarts HJ, Snaas-Alders S, Bekkenkamp-Grovenstein M and van Schothorst EM: Effects of dietary history on energy metabolism and physiological parameters in C57BL/6J mice. Exp Physiol 98: 1053-1062, 2013.
44. Cappellano G, Morandi EM, Rainer J, Grubwieser P, Heinz K, Wolfram D, Bernhard D, Lobenwein S, Pierer G and Ploner C: Human macrophages preferentially infiltrate the superficial adipose tissue. Int J Mol Sci 19: E1404, 2018.

45. Ludgero-Correia A Jr, Aguila MB, Mandarim-de-Lacerda CA and Faria TS: Effects of high-fat diet on plasma lipids, adiposity, and inflammatory markers in ovariectomized C57BL/6 mice. Nutrition 28: 316-323, 2012

46. Mechanick JI, Zhao S and Garvey WT: The adipokine-cardiovascular-lifestyle network: Translation to clinical practice. J Am Coll Cardiol 68: 1785-1803, 2016.

47. Fasshauer M and Blüher M: Adipokines in health and disease. Trends Pharmacol Sci 36: 461-470, 2015.

48. Engin A: Adiponectin-resistance in obesity. Adv Exp Med Biol 960: 415-441, 2017.

49. Achari AE and Jain SK: Adiponectin, a therapeutic target for obesity, diabetes, and endothelial dysfunction. Int J Mol Sci 18: E1321, 2017.

50. Khan M and Joseph F: Adipose tissue and adipokines: The association with and application of adipokines in obesity. Scientifica (Cairo) 2014: 328592, 2014.

51. Kopp A, Bala M, Weigert J, Büchler C, Neumeier M, Aslanidis C, Schölmerich $\mathrm{J}$ and Schäffler A: Effects of the new adiponectin paralogous protein CTRP-3 and of LPS on cytokine release from monocytes of patients with type 2 diabetes mellitus. Cytokine 49: 51-57, 2010.

52. Zand H, Morshedzadeh N and Naghashian F: Signaling pathways linking inflammation to insulin resistance. Diabetes Metab Syndr 1 (Suppl 11): S307-S309, 2017.

53. De Felice FG and Ferreira ST: Inflammation, defective insulin signaling, and mitochondrial dysfunction as common molecular denominators connecting type 2 diabetes to Alzheimer disease. Diabetes 63: 2262-2272, 2014. 